\title{
Deuterium-depleted water inhibits human lung carcinoma cell growth by apoptosis
}

\author{
FENG-SONG CONG ${ }^{1}$, YA-RU ZHANG ${ }^{1}$, HONG-CAI SHENG ${ }^{2}$, \\ ZONG-HUAAO ${ }^{2}$, SU-YI ZHANG ${ }^{2}$ and JU-YONG WANG ${ }^{3}$ \\ ${ }^{1}$ College of Life Sciences and Technology, Shanghai Jiaotong University, Shanghai 200240; \\ ${ }^{2}$ The Technology Centre, Luzhoulaojiao Co., Ltd., Sichuan 646000; ${ }^{3}$ Department of Oncology, \\ Longhua Hospital, Shanghai University of Traditional Chinese Medicine, Shanghai 200032, P.R. China
}

Received September 28, 2009; Accepted November 12, 2009

DOI: $10.3892 /$ etm_00000043

\begin{abstract}
To investigate the in vivo and in vitro inhibitory effects of deuterium-depleted water (DDW) on human lung cancer and the possible mechanisms underlying these effects, we cultured and treated human lung carcinoma cell line A549 and human embryonic lung fibroblasts HLF-1 with various concentrations of DDW from 2 to $72 \mathrm{~h}$. Cellular growth inhibition rates were determined using the 3-(4, 5-dimethyldiazol-2-yl)-2, 5-diphenyltetrazolium-bromide) (MTT) proliferation assay. A549 cells were treated with $50 \pm 5 \mathrm{ppm}$ DDW, and the morphology and structure of cells were observed by scanning electron microscopy (SEM). We observed alterations in the cellular skeleton by transmission electron microscopy (TEM) and changes in cell cycle by flow cytometry. Our data showed that DDW significantly inhibited the proliferation of A549 cells at a specific time point, and cells demonstrated the characteristic morphological changes of apoptosis under SEM and TEM. The length of the S phase increased significantly in cells treated with $50 \mathrm{ppm}$ DDW, whereas the G0 to G1 phase and G2 to M phase were decreased. We observed DDW-induced cellular apoptosis using terminal deoxynucleotidyl transferase dUTP nick end labeling (TUNEL) and DNA fragment analyses. In addition, we established a tumor transplantion model by injecting $\mathrm{H} 460$ tumor cells into subcutaneous tissue of BALB/c mice treated with DDW for 60 days. We determined the tumor inhibition rate of treated and control groups and found that the tumor weight was significantly decreased and the tumor inhibition rate was approximately $30 \%$ in the DDW group. We conclude that DDW is a promising new anticancer agent with potential for future clinical application.
\end{abstract}

Correspondence to: Dr Feng-Song Cong, Department of Biotechnology, College of Life Sciences and Technology, Shanghai Jiaotong University, 800 Dongchuan Road, Minhang District, Shanghai 200240, P.R. China

E-mail: fscong@sjtu.edu.cn

Key words: deuterium-depleted water, lung cancer, inhibition, apoptosis

\section{Introduction}

Lung cancer is one of the leading causes of death by cancer worldwide; approximately $80 \%$ of lung cancers can be histologically classified as non-small cell lung cancers (NSCLCs). Most patients present with locally advanced $(37 \%)$ or metastatic $(38 \%)$ disease at the time of diagnosis (1). Despite advances in chemotherapy, the average 5-year survival rate for patients with advanced NSCLC remains extremely poor (2), thus new agents are needed to establish an effective therapeutic strategy against NSCLC. There is great interest in developing new preventive and anti-tumor agents that are more effective and less toxic. It has recently been suggested that deuterium-depleted water (DDW) may play a potentially beneficial role in cancer prevention (3).

In nature, the ratio between deuterium and hydrogen $(\mathrm{D} / \mathrm{H})$ in ordinary water is approximately 1:6600 (4). It has been known for decades that the mass difference between hydrogen and deuterium leads to differences in the physical and chemical behavior of the two stable isotopes $(5,6)$. In biological systems, the effect of replacing hydrogen with deuterium has also been well documented $(7,8)$. Early studies revealed that the life span of mice with ascites tumors was prolonged by drinking $25-30 \%$ deuterium water (deuterated water) (9), and the mortality caused by ${ }^{60} \mathrm{Co}$ irradiation in mice was significantly decreased by drinking $30 \%$ deuterated water (10). Gross and Spindel discovered that high concentrations of deuterium in water induced stagnation mitosis (11). Although the high concentration of deuterium in water was able to inhibit cell proliferation by mitosis arrest and to protect the cell from radiation, it also reduced the life span of mice and even resulted in death $(12,13)$, which limits its clinical application.

To date, research into the effects of deuterium in organisms has focused primarily on deuterated water; little research has been conducted on DDW. The possible role of naturally occurring deuterium in biological systems was first investigated in the early 1990s. DDW was shown to significantly decrease the growth rate of $\mathrm{L}_{929}$ fibroblast cell lines in vitro, and also inhibit tumor growth in xenotransplanted mice (14). Scientists have recently reported the anti-tumor characteristics of DDW when the deuterium volume fraction in normal water was 
reduced by $65 \%$ (15-17); however, the mechanism underlying the anti-tumor effect of DDW is still unknown. In this study, we investigated the in vivo and in vitro effects of DDW on the growth of human lung cancer and the possible mechanisms of these effects.

\section{Materials and methods}

Materials. DDW was provided by Shanghai Chitian DDWater Bioengineering Co., Ltd. (Shanghai, China). A549 and H460 cells were purchased from the Cell Research Institute of the Chinese Medical Research Academy (Shanghai, China), and human embryonic lung fibroblasts (HLF-1 cells) were purchased from the cell bank of the Chinese Academy of Science (Shanghai, China).

Cell culture. The human lung carcinoma A549 and H460 cell lines were maintained in RPMI-1640 medium (Gibco, USA) containing $10 \%$ fetal bovine serum (FBS; Si Jiqing, HangZhou, China) at $37^{\circ} \mathrm{C}$ in $5 \% \mathrm{CO}_{2}$. For in vitro studies, the cells were seeded in $25 \mathrm{ml}$ cell culture bottles and grown in complete medium to $90 \%$ confluence. Then, cells were washed with phosphate-buffered saline (PBS) and incubated for $48 \mathrm{~h}$ at $37^{\circ} \mathrm{C}$ in $6 \mathrm{ml}$ of serum-free medium containing DDW.

HLF-1 cells were maintained in $\alpha$-MEM medium (Genom, HangZhou, China), containing $10 \% \mathrm{FBS}$ at $37^{\circ} \mathrm{C}$ in $5 \% \mathrm{CO}_{2}$.

Analysis of cytotoxicity. The cytotoxicity of DDW was measured in A549 and HLF-1 cells every $2 \mathrm{~h}$ for $24 \mathrm{~h}$ by the 3-(4,5-dimethyldiazol-2-yl)-2,5-diphenyltetrazolium-bromide (MTT; Kai Ji Co. Ltd., Nan Jing, China) colorimetric assay. A preliminary study was conducted to determine the optimal concentration of DDW and the length of treatment. A549 and HLF-1 cells were cultured in DDW (25, 50 or $105 \mathrm{ppm})$ and normal water in 96 -well plates at $2 \times 10^{4}$ cells $/ 100 \mu$ l well or $1 \times 10^{4}$ cells $/ 100 \mu \mathrm{l}$ well, respectively. Cytotoxicity was determined 24, 48 and $72 \mathrm{~h}$ after treatment. The MTT proliferation assay is based on the ability of mitochondrial dehydrogenase in viable cells to convert the MTT reagent into a soluble blue formazan dye. At the end of the culture period, $50 \mu \mathrm{l}$ of the MTT reagent was added, and cells were incubated for $4 \mathrm{~h}$ at $37^{\circ} \mathrm{C}$. After removal of the culture medium, cells were lysed with dimethyl sulfoxide (DMSO) to determine the amount of formazan product. The dishes were placed on a shaking platform until the formazan crystals were dissolved. Absorption was measured by a microplate reader (Multiskan MK3; Shanghai, China) at $550 \mathrm{~nm}$, and the results were expressed as percent decrease in cell viability compared to the controls (3). Each cell sample was measured three times, and the mean was reported.

Transmission electron microscopy (TEM). A549 monolayer cells were treated with DDW at $50 \pm 5 \mathrm{ppm}$ for $10 \mathrm{~h}$, $72 \mathrm{~h}$ or 40 days and subsequently collected and fixed with $25 \%$ glutaraldehyde in $0.2 \mathrm{M}$ PBS ( $\mathrm{pH} \mathrm{7.4)}$ at $4^{\circ} \mathrm{C}$ for $2 \mathrm{~h}$. A549 cells were fixed with osmic acid and dehydrated in graded ethanol solutions before embedding. After staining, samples were analyzed using TEM (CM 120; Philips, The Netherlands).
Microscopy. After incubation with $50 \pm 5$ ppm DDW for 40 days, changes in morphology and structure of A549 cells were observed by fluoroscope microscopy (Olympus, Japan). In addition, membrane morphology was observed by SEM (Multimode Nanoscope IIIa; Digital Instrument Co., USA). For SEM, A549 cells were collected and seeded on a glass overnight and then fixed for 15 min with $0.25 \%$ glutaric dialdehyde. Cells were dried and sprayed with gold after dehydration.

Flow cytometric analysis. Cells were harvested by trypsinization after DDW treatment (10 or $72 \mathrm{~h}$ ), washed twice with PBS and then re-suspended in ice-cold PBS and fixed with $70 \%$ ethanol. After the ethanol was removed, the cells were washed once in PBS. The cells were then centrifuged, and cell pellets were re-suspended in $1 \mathrm{ml}$ propidium iodide (PI)/Triton X-100 staining solution (0.1\% Triton X-100 in PBS, $0.2 \mathrm{mg} / \mathrm{ml} \mathrm{RNase}$ A and $10 \mu \mathrm{g} / \mathrm{ml} \mathrm{PI}$ ) and incubated at least $30 \mathrm{~min}$ at room temperature. The stained cells were analyzed using a FACScan flow cytometer in combination with BD Lysis II software (BD Co., USA).

Terminal deoxynucleotidyl transferase dUTP nick end labeling (TUNEL) staining. Cells were treated with $50 \mathrm{ppm}$ DDW for 48 or $72 \mathrm{~h}$, seeded on polylysine-coated slides, fixed with $4 \%$ paraformaldehyde in $0.1 \mathrm{M} \mathrm{PBS}$ for $1 \mathrm{~h}$ at $25^{\circ} \mathrm{C}$, and then permeabilized with $1 \%$ Triton X-100 in $0.01 \mathrm{M}$ citrate buffer (pH 6.0). DNA fragmentation was detected using a TUNEL detection kit (Kai Gene, Nan Jing, China), which specifically labeled the 3' hydroxyl terminus of DNA strand breaks using fluorescein isothiocyanate (FITC)-conjugated dUTP. DNA was also labeled with FITC DNA-binding dye for $5 \mathrm{~min}$. FITC labels were observed with a fluorescence microscope. As a positive control, A549 cells were incubated in culture media without DDW for $48 \mathrm{~h}$ and treated with DNase I. The percentage of apoptotic cells was calculated as the number of apoptotic cells divided by the total number of cells.

Electrophoresis of DNA fragments. A549 cells were treated with 50 ppm DDW for $10,24,48$ or $72 \mathrm{~h}$. DNA and the DNA marker TrackIt $1 \mathrm{~kb}$ Plus Ladder (Kai Gene) were separated on $1.5 \%$ agarose gels.

Animal experiment. Male BALB/c nude mice (weight $20 \pm 2 \mathrm{~g}$ ) were purchased from the ShangHai SLAC Laboratory Animal Co. Ltd. (Shanghai, China). The 8-week-old mice used in this study were maintained in a specific pathogen-free environment. Animal care and maintenance were carried out in accordance with the Guide for the Care and Use of Laboratory Animals by Long Hua Hospital, Shanghai, China.

For in vivo studies, the mice were randomly divided into two groups of 8 animals each; the model group and DDW-treated group. The model group mice and DDW-treated group mice drank tap water and DDW, respectively. To construct the H460 xenograft model, cells were harvested after 14 days by trypsinization, washed twice with PBS and re-suspended at $1 \times 10^{7}$ cells $/ \mathrm{ml}$. Approximately $2 \times 10^{6} \mathrm{H} 460$ cells were injected subcutaneously into the right hind flank of all mice. Animals were provided with DDW or tap water continually until the end of the experiment. 
A

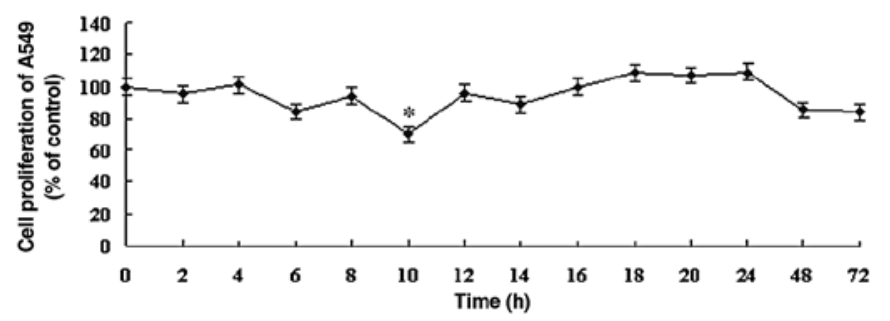

B

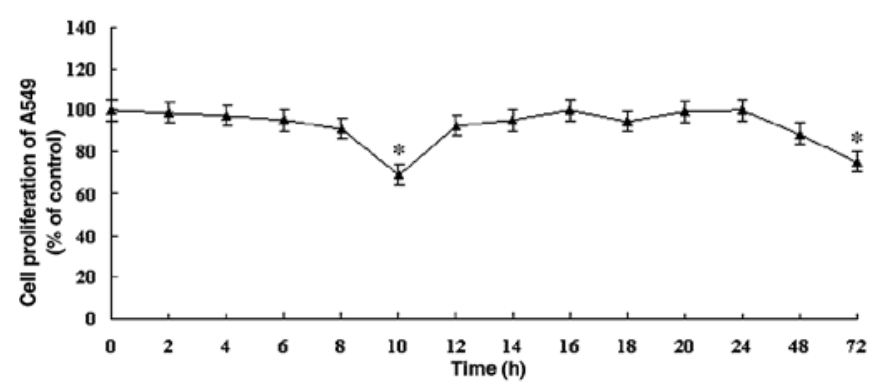

C

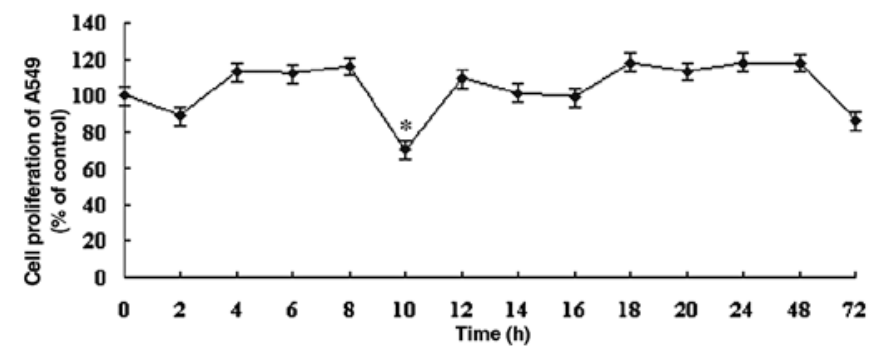

Figure 1. DDW inhibited the growth rate of A549 cells. Cells were treated with DDW for different times and at various concentrations: (A) 25, (B) 50 and (C) $105 \mathrm{ppm}$. The cell growth was determined using the MTT cell proliferation assay. Results are expressed as the percentage of cell growth relative to the untreated control cells. The data are presented as mean $\pm \mathrm{SD}$. ${ }^{*} \mathrm{P}<0.05$ vs. control.

Specimen preparation. Experimental pulmonary metastases were established by inoculation of $2 \times 10^{6} \mathrm{H} 460$ cells. Two months later, the $\mathrm{H} 460$ xenograft model mice were sacrificed, and the tumors were weighed. The tumor inhibition rate was calculated using the following formula: tumor inhibition rate $=$ (tumor weight of control group - tumor weight of treatment group)/tumor weight of control group x $100 \%$.

Statistical analysis. Data are expressed as the mean \pm SD. Differences between groups were analyzed by analysis of variance (ANOVA) or the Student's t-test. Analyses were performed with SPSS software version 13.0 (SPSS Inc., IL, USA). A P-value $<0.05$ was considered statistically significant.

\section{Results}

DDW inhibits the growth rates of A549 and HLF-1 cells. To determine the optimal DDW treatment in the A549 human lung carcinoma cell line, the effect of DDW was assessed using the MTT cell proliferation assay. The effects of DDW on the growth and functional integrity of A549 cells are shown in
A

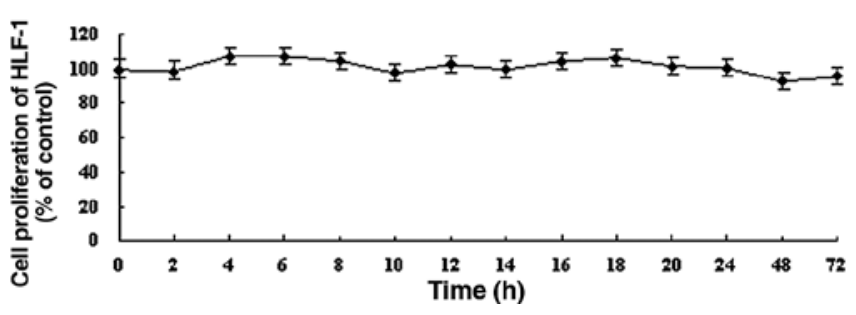

B

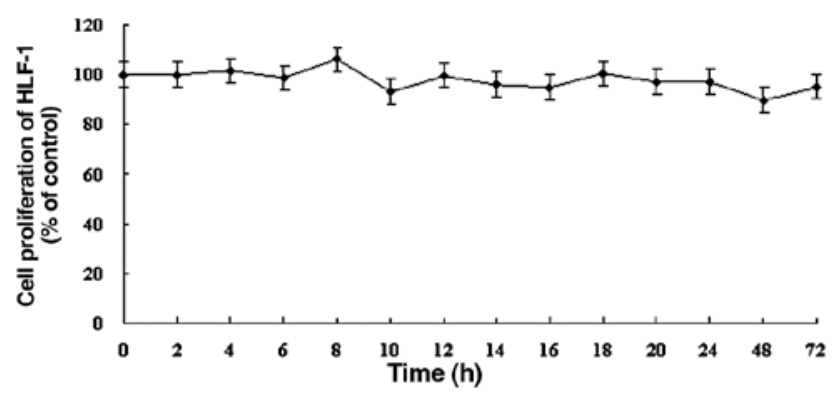

C

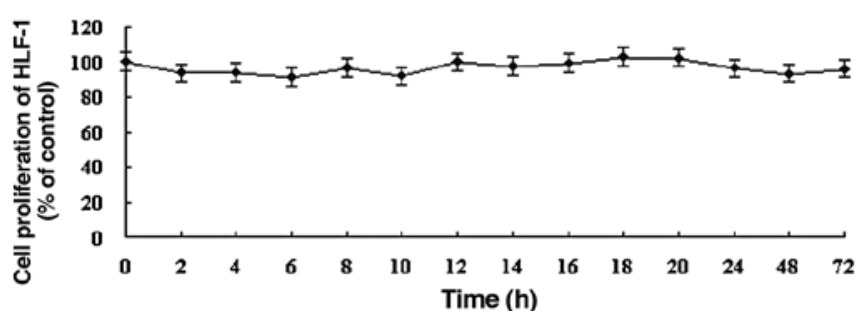

Figure 2. The effect of DDW on the growth of HLF-1 cells. Cells were treated with DDW for different times and at various concentrations: (A) 25, (B) 50 and (C) $105 \mathrm{ppm}$. The cell growth was determined using the MTT cell proliferation assay. Results are expressed as the percentage of cell growth relative to the untreated control cells. The data are presented as mean $\pm \mathrm{SD}$.

Fig. 1. There were no significant changes in the growth rate until $10 \mathrm{~h}$ of exposure to DDW. At $10 \mathrm{~h}$, cell viability of the treated cells $(25,50$ or $105 \mathrm{ppm}$ DDW) decreased significantly to $70.39,68.93$ and $69.90 \%$, respectively, compared to the untreated controls (Fig. 1). The cell growth rate subsequently returned to the level of the controls at $48 \mathrm{~h}$. After $72 \mathrm{~h}$, cell viability at different DDW concentrations decreased to 84.11, 75.23 and $86.44 \%$ of control cells, respectively.

In contrast, DDW did not significantly alter the growth of human embryonic lung fibroblast HLF-1 cells compared to controls during the $72 \mathrm{~h}$ treatment (Fig. 2). Based on these results, we chose to use 50 ppm DDW and A549 cells for subsequent experiments.

DDW treatment alters A549 cell morphology and structure. We observed the morphology and structure of A549 cells by TEM. Untreated A549 cells showed a flattened profile of cell morphology. There were no alterations to mitochondria, rough or smooth endoplasmic reticulum, Golgi apparatus, lamellar bodies or karyon (Fig. 3A). To observe DDW-induced morphological changes, we incubated A549 cells with $50 \pm 5$ ppm DDW for 10 or $72 \mathrm{~h}$. After a 10-h treatment, a few myelin bodies 
A

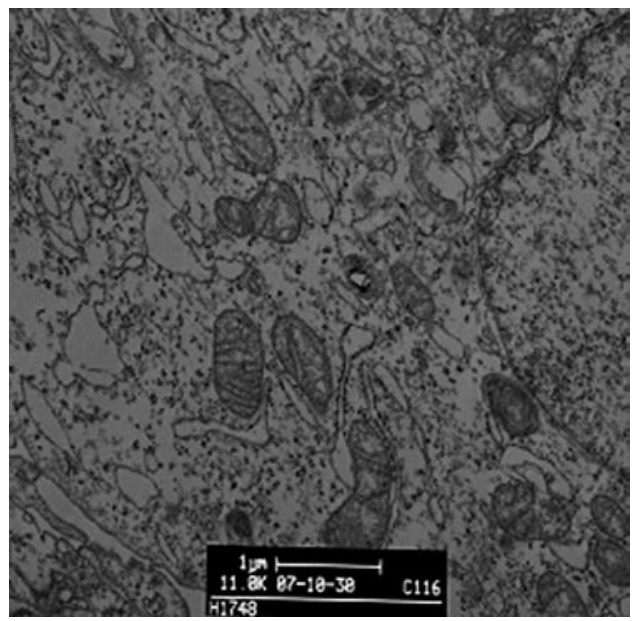

B

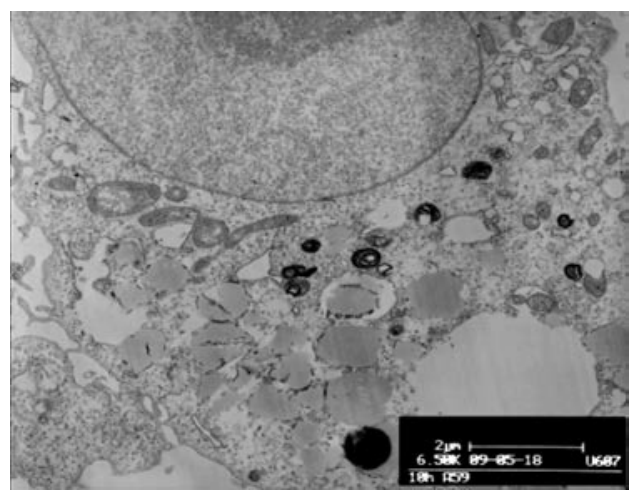

C

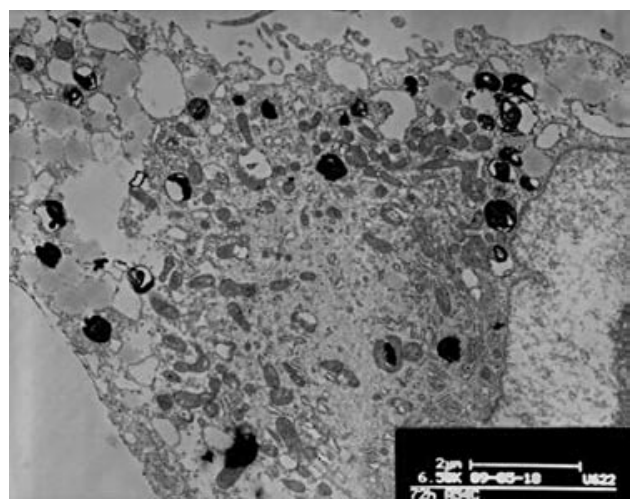

D

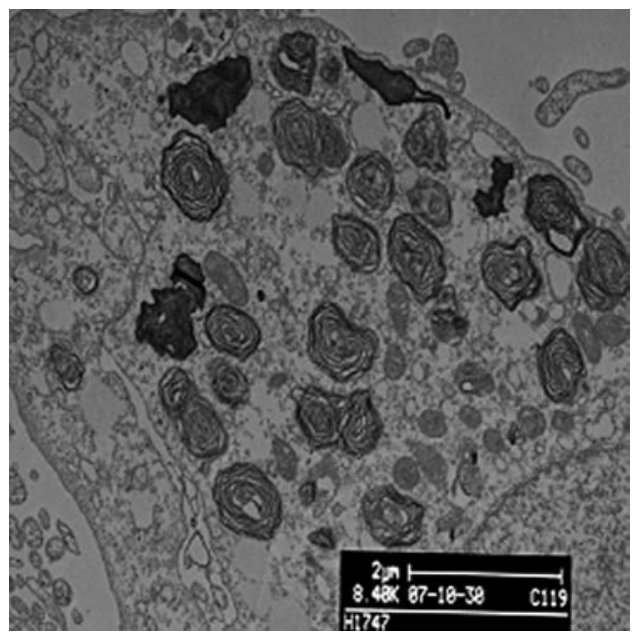

Figure 3. Representative transmission electron microscopy images of A549 cells treated with DDW for $10 \mathrm{~h}, 72 \mathrm{~h}$ or 40 days. (A) Control group (magnification x11,800), (B) 10-h DDW treatment (magnification x6500), (C) 72-h DDW treatment (magnification $\mathrm{x} 6500$ ) and (D) 40-day DDW treatment (magnification $\mathrm{x} 8480)$ (A, bar=1 $\mu \mathrm{m} ; \mathrm{B}, \mathrm{C}$ and $\mathrm{D}$, bar=2 $\mu \mathrm{m})$.
A

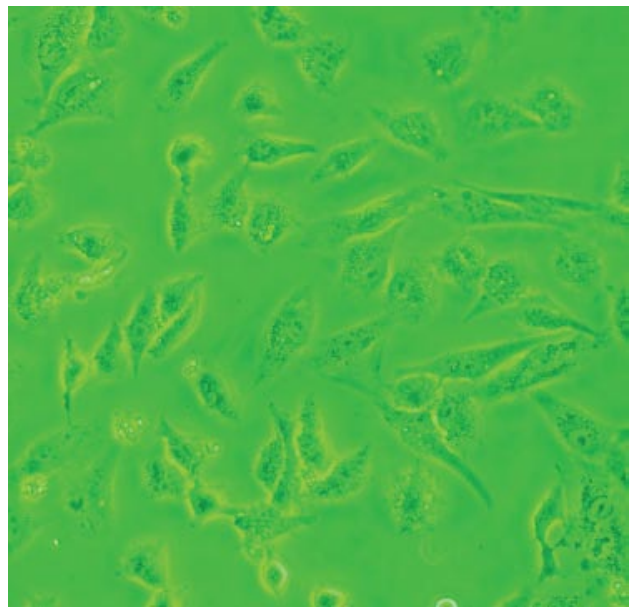

B

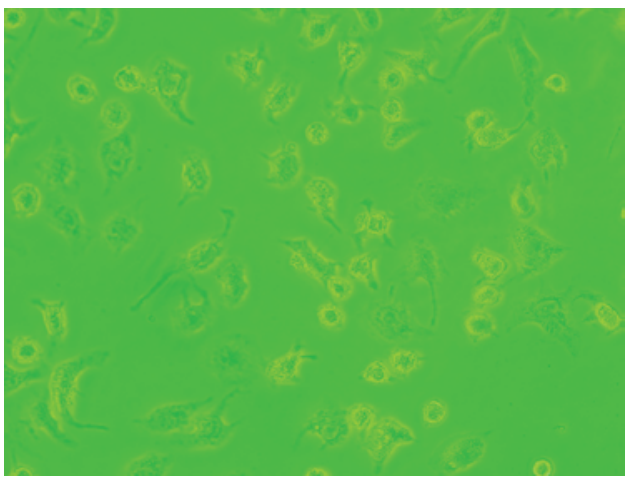

Figure 4. Representative microscopy images of A549 cells treated with DDW for 40 days. Compared to untreated control cells cultured in RPMI-1640, cell morphology was modified by incubation with $50 \pm 5$ ppm DDW. Magnification x640.

and physalides were observed in the cytoplasm (Fig. 3B), and more myelin bodies and physalides were apparent after $72 \mathrm{~h}$ of treatment.

Cells exposed to DDW exhibited modified morphology, which was more pronounced after 40 days of treatment. Untreated control cells were shuttle-shaped or kidney-shaped (Fig. 4A), but they changed to an amorphous polygon when treated with DDW (Fig. 4B). Using SEM and TEM, we observed submicroscopic changes in the morphology. Under SEM, untreated control cells showed a smooth profile and more extracellular matrix than those exposed to DDW (Fig. 5A and B). In contrast, A549 cells exposed to DDW had a rough profile and numerous microvilli on the cell surface (Fig. 5C and D). Under TEM, DDW-treated cells showed numerous myelin bodies in the cytoplasm (Fig. 3D); however, these changes were not observed in the control cells.

DDW treatment alters the cell cycle. To determine whether DDW alters the cell cycle in A549 cells, we stained the cells with PI and used flow cytometry to assess the sub-G1 population. Whereas no significant changes were found in the proportion of cells in the sub-G1 phase between the control cells and DDW-treated cells at $10 \mathrm{~h}(3.24$ and 4.41\%, respectively), a significant increase in the proportion of cells in the sub-G1 phase was observed in cells treated for $72 \mathrm{~h}$ (6.24 vs. 3.24\%; Fig. 6). Meanwhile, cell cycle alterations in 
$\mathbf{A}$

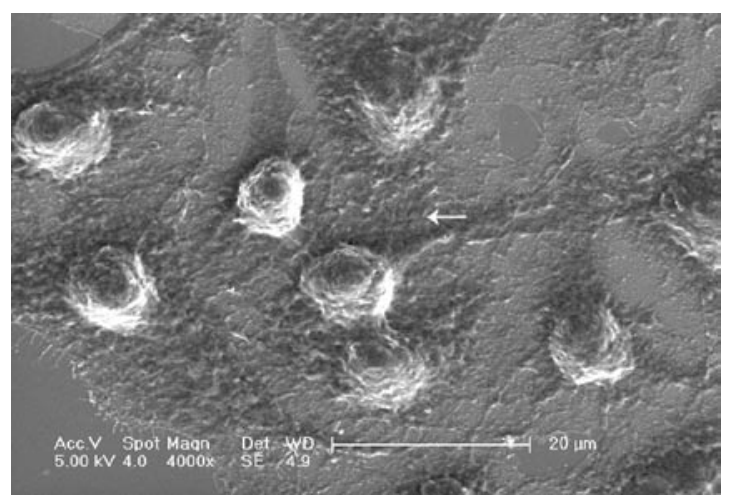

B

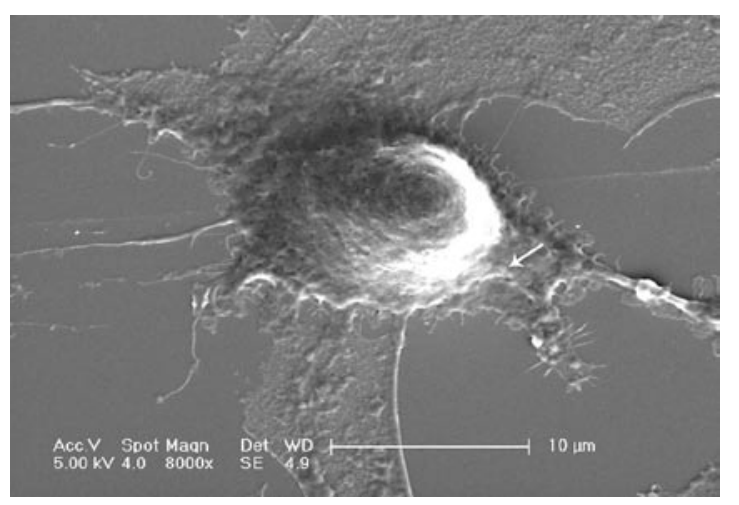

C

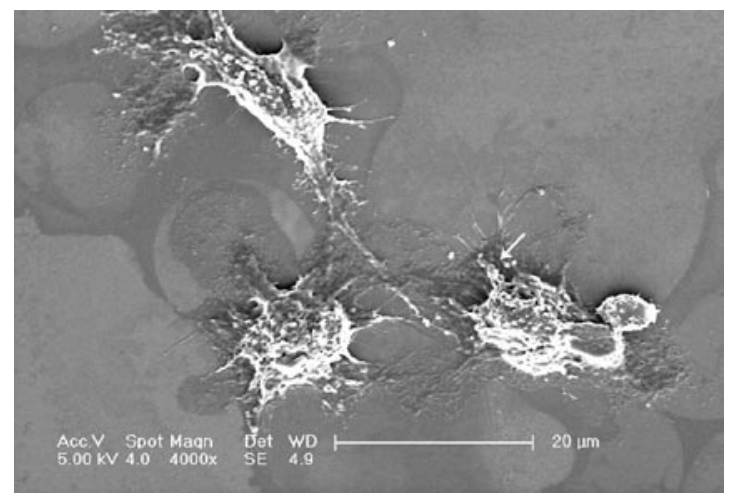

D

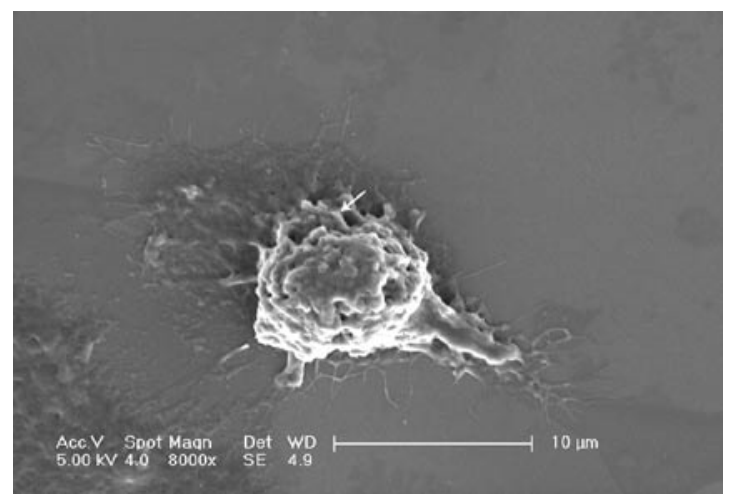

Figure 5. Representative scan electron microscopy images of A549 cells. A and B (magnification $\mathrm{x} 4000$ and $\mathrm{x} 8000$, respectively) display the shape of normal A549 cells. C and D (magnification x4000 and x8000, respectively) display the cells modified by treatment with DDW for 40 days (A and C, bar $=20 \mu \mathrm{m}$; B and D, bar=10 $\mu \mathrm{m}$ ). Arrows point to microvilli.

DDW-treated cells were analyzed by flow cytometry. The $\mathrm{S}$ phase increased whereas the G0 to G1 phase and G2 to M phase were reduced in DDW-treated cells compared to the control cells (Table I; Fig. 6).
A

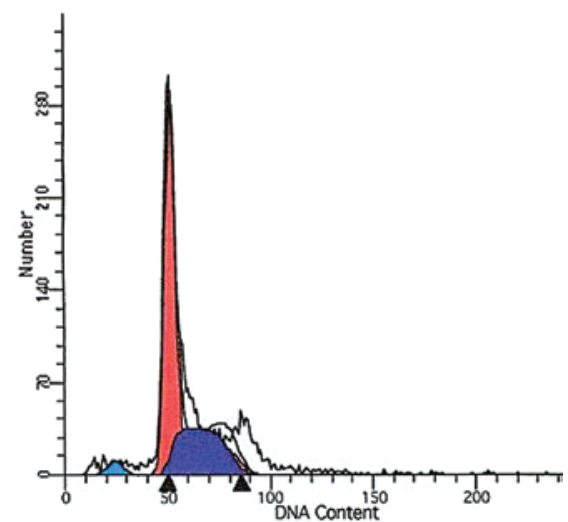

B

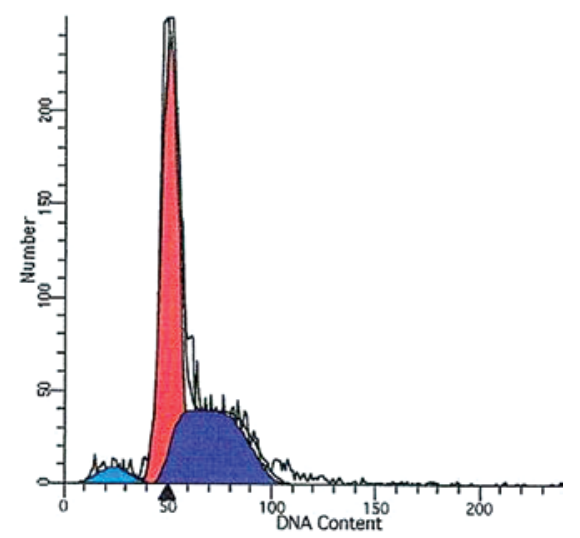

C

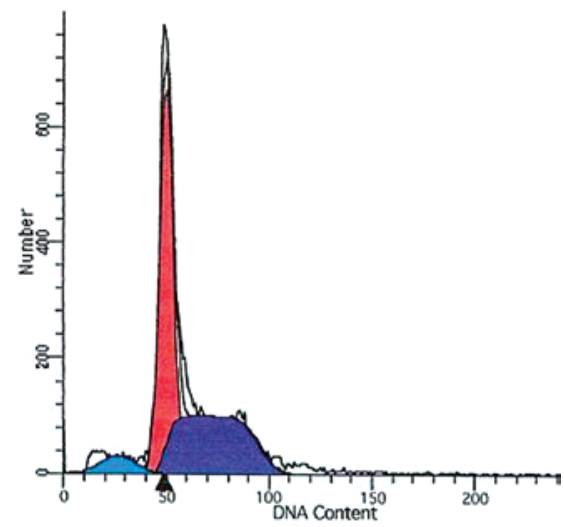

Figure 6. Cell cycle analysis of DDW-treated A549 cells by flow cytometry. The percentage of non-apoptotic and apoptotic cells in each cycle was observed by flow cytometry. The data is presented as mean $\pm \mathrm{SD}(\mathrm{n}=3)$. (A) Control group, (B) 10-h DDW treatment and (C) 72-h DDW treatment.

DDW-induced cell apoptosis. To ascertain whether DDW induces apoptosis in A549 cells, we treated cells with $50 \mathrm{ppm}$ DDW and observed DDW-induced apoptosis with the TUNEL assay (Fig. 7A). Apoptosis was evident in $31.39 \pm 2.54 \%$ of cells at $48 \mathrm{~h}$ and $25.38 \pm 3.90 \%$ at $72 \mathrm{~h}$. The increased apoptosis was significant compared with the untreated control group $(10.87 \pm 1.11 \%$; $\mathrm{P}<0.05$, Student's t-test). DNA was extracted and analyzed by electrophoresis. As shown in Fig. 7B, fragmented DNA was observed in cells treated with DDW for 48 or $72 \mathrm{~h}$.

DDW influences tumor inhibition rates in vivo. We investigated whether DDW inhibits the growth of transplanted 
Table I. Cell cycle population in A549 cells (mean \pm SD).

\begin{tabular}{lrcr}
\hline Cycle & \multicolumn{1}{c}{ Control } & \multicolumn{1}{c}{$10 \mathrm{~h}$} & \multicolumn{1}{c}{$72 \mathrm{~h}$} \\
\hline Sub-G1 & $3.24 \pm 0.78$ & $4.41 \pm 0.37^{\mathrm{a}}$ & $6.24 \pm 0.55^{\mathrm{a}}$ \\
G0-G1 & $60.11 \pm 2.15$ & $58.63 \pm 2.40$ & $55.23 \pm 1.47$ \\
S phase & $32.65 \pm 0.78$ & $38.47 \pm 0.29^{\mathrm{a}}$ & $44.03 \pm 0.35^{\mathrm{a}}$ \\
G2-M & $7.24 \pm 1.37$ & $2.90 \pm 0.08^{\mathrm{a}}$ & $0.75 \pm 0.01^{\mathrm{a}}$ \\
\hline
\end{tabular}

${ }^{\mathrm{a}} \mathrm{P}<0.05$ vs. control; t-test.

Table II. Tumor weight and inhibition rates of nude mice.

\begin{tabular}{lccc}
\hline Group & $\mathrm{n}$ & $\begin{array}{c}\text { Tumor weight } \\
(\mathrm{g})\end{array}$ & $\begin{array}{c}\text { Inhibition } \\
\text { rates }(\%)\end{array}$ \\
\hline Control & 8 & $10.64 \pm 0.83$ & - \\
DDW & 8 & $7.36 \pm 0.78^{\mathrm{a}}$ & 30.80 \\
\hline
\end{tabular}

${ }^{\mathrm{a}}<0.05$; t-test.

tumors in mice. After drinking DDW for 60 days, tumor growth in nude mice was considerably reduced. We observed a significant decrease by $30.80 \%$ on tumor inhibition rates in the DDW group (Table II).

\section{Discussion}

In this study, we investigated the in vitro effects of DDW on growth rate, morphology and structure of cells, cell cycle distribution and apoptosis. We found that DDW significantly suppressed the proliferation of A549 cells at $10 \mathrm{~h}$. This inhibitory effect disappeared from 12 to $24 \mathrm{~h}$, but returned during the prolonged 48- or 72-h treatment. In contrast, DDW exerted no significant effects on HLF-1 cells, indicating a cell-specific response to DDW treatment or a more rapid adaptation for HLF-1 cells compared with A549 cells.

A previous study demonstrated that $30 \mathrm{ppm}$ DDW significantly decreased the growth rate of $\mathrm{L}_{929}$ fibroblast cells and also inhibited tumor growth in xenotransplanted mice. Deuterium is crucial to the start of cell proliferation as the lag period is 6-8 $\mathrm{h}$ longer in medium with low D content (14). DDW also affects seed germination; inhibition of germination was highest 5-6 days after the beginning of germination, but the inhibition was not observed after 10-12 days (18). In addition, the biological effects of DDW on plant cells were investigated in a previous study. In the first half hour of DDW treatment, plants showed biochemical changes similar to those induced by dark treatment; respiration increased, photosynthesis stopped and intracellular $\mathrm{pH}$ became alkaline, whereas extracellular $\mathrm{pH}$ became more acidic. Maximum effects were noted $30 \mathrm{~min}$ after treatment, and then cells gradually returned to normal (19). The results in the present study are remarkably similar to those of previous studies.

Cell division is sensitive to intracellular changes in deuterium concentration, and a normal concentration of deuterium
A

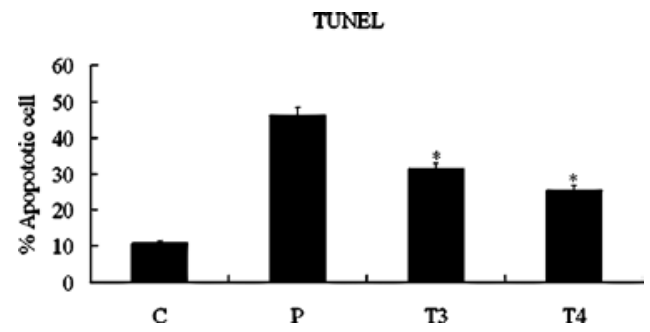

B

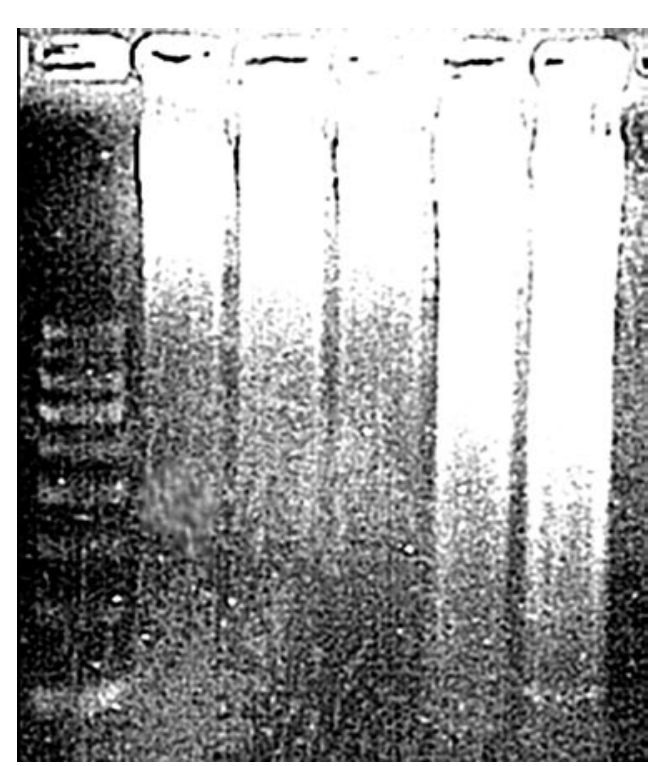

Figure 7. Assessment of cell apoptosis by TUNEL (A) and DNA fragment (B) analyses. A549 cells were treated with 50 ppm DDW for 10 (T1), 24 (T2), 48 (T3) or $72 \mathrm{~h}$ (T4). C, control group; P, DNase I-treated A549 cells as positive control ( ${ }^{*} \mathrm{P}<0.05$ vs. control).

is essential to initiate and to maintain normal cellular growth (14). Our results appear to support the hypothesis of Laskey et al, who hypothesized that mechanisms exist in both animal and plant cells that detect changes in deuterium concentration (19). It is necessary to reach the threshold of intracellular $\mathrm{D} / \mathrm{H}$ to initiate cell division. When cells are cultured in a medium with low deuterium concentration, proliferation is inhibited due to the increased time required to reach the appropriate $\mathrm{D} / \mathrm{H}$ ratio. In higher organisms, a regulatory system has developed over millions of years, which is sensitive to intracellular changes in $\mathrm{D} / \mathrm{H}$. The $\mathrm{D} / \mathrm{H}$ ratio can increase more rapidly in normal than in tumor cells (19). Tumor cells have a higher growth rate than normal cells as a result of consuming a greater quantity of deuterium (20). We observed that in vitro proliferation of tumor cells was inhibited by DDW, whereas proliferation of normal cells was not, suggesting that DDW may influence the $\mathrm{D} / \mathrm{H}$ ratio in tumor cells, which, in turn, affects the growth rate.

In the present study, we found that DDW increases the $S$ phase cell population and inhibited the proliferation of A549 cells. A greater proportion of DDW-treated A549 cells were arrested at S phase at 72 than at $10 \mathrm{~h}$, as observed by flow cytometry. The cell cycle regulatory system appeared to perceive the $\mathrm{D} / \mathrm{H}$ ratio, and at the threshold level it triggered the molecular mechanism that finally caused the cell to enter into the $\mathrm{S}$ phase (19).

Cell apoptosis via intracellular mechanisms leads to cell death. Many agents have been discovered to treat cancers by 
inducing an abnormal cell cycle and apoptosis. Thus DDW may have potential as a cancer therapy. Using TUNEL and DNA fragment analyses we showed that DDW significantly increased the number of apoptotic cells after $48 \mathrm{~h}$, indicating that DDW may trigger a molecular mechanism to induce cells to apoptosis. Gyongyi and Somlyai found reduced expression of C-myc, Ha-ras and P53 in six different organs (spleen, lung, thymus, kidney, liver and lymph nodes) of nude mice in the DDW-treated group (21). They suggested that naturally occurring deuterium may be involved in the regulation of genes that play important roles in the cell cycle or tumor development (21). Therefore, future studies exploring the molecular mechanism of DDW-induced apoptosis are vital to elucidate its tumor-inhibitory effects.

Our in vivo results revealed that DDW significantly inhibited tumor growth. However, we do not know whether the effect was caused by cell apoptosis. Further studies are needed to elucidate the mechanism of DDW-induced tumor inhibition in vivo.

In summary, we found that DDW exerts effects on the cell cycle and changes in configuration and induces apoptosis in vitro. We also found that DDW inhibits tumor growth in xenotransplanted mice. Collectively, these findings suggest the potential for DDW as an anti-tumor drug with clinical application.

\section{Acknowledgements}

We acknowledge the financial support from the Technology Centre of Luzhoulaojiao Co., Ltd. for the Top DeuteriumDepleted Liquor Research Program.

\section{References}

1. Carney DN: Lung cancer - time to move on from chemotherapy. N Engl J Med 346: 126-128, 2002.

2. Nishio K, Nakamura T, Koh Y, et al: Drug resistance in lung cancer. Curr Opin Oncol 11: 109-115, 1999.

3. Swisher S and Roth JA: Clinical update of Ad-p53 gene therapy for lung cancer. Surg Oncol Clin N Am 11: 521-535, 2002.
4. Criss RE: Principles of Stable Isotope Distribution. Oxford University Press, New York, pp234, 1999.

5. Collins CJ and Bowman NS (eds): Isotope Effects in Chemical Reactions. Van Nostrand Reinhold, New York, pp286-363, 1971.

6. Wiberg KB: The deuterium isotope effect. Chem Rev 55: 713-743, 1955.

7. Jancso G and van Hook WA: Condensed phase isotope effects: especially vapor pressure isotope effects. Chem Rev 74: 689-750, 1974.

8. Rundel PW, Ehleringer JR and Nagy KA: Stable Isotope in Ecological Research. Springer, New York, pp7-9, 1988.

9. Hughes AM, Tolbert BM, Lonberg-Holm K, et al: The effect of deuterium oxide on survival of mice with ascites tumor. Biochim Biophys Acta 28: 58-61, 1958.

10. Laissue JA, Bally E, Joel DD, et al: Protection of mice from whole-body gamma radiation by deuteration of drinking water. Radiat Res 96: 59-64, 1983.

11. Gross PR and Spindel W: Heavy water inhibition of cell division: an approach to mechanism. Ann NY Acad Sci 90: 500-522, 1962.

12. Katz JJ, Crespi HL, Czajka DM, et al: Course of deuteriation and some physiological effects of deuterium in mice. Am J Physiol 203: 907-913, 1962.

13. Katz JJ, Crespi HL and Hasterlik RJ: Some observations on biological effects of deuterium with special reference to effects on neoplastic processes. J Natl Cancer Inst 18: 641-659, 1957.

14. Somlyai G, Jancsó G, Jákli G, et al: Naturally occurring deuterium is essential for the normal growth rate of cells. FEBS Lett 317: 1-4, 1993.

15. Siniak IuE, Turusov VS, Grigorev AI, et al: Consideration of the deuterium-free water supply to an expedition to Mars. Aviakosam Ekolog Med 37: 60-63, 2003.

16. Turusov VS, Siniak IuE, Grigor'ev AI, et al: Low-deuterium water effect on transplantable tumors. Vopr Onkol 51: 99-102, 2005.

17. Tyrysov VS, Siniak IuE, Antoshina EE, et al: The effect of preliminary administration of water with reduced deuterium content on the growth of transplantable tumors in mice. Vopr Onkol 52: 59-62, 2006.

18. Somlyai G: Defeating cancer! The biological effect of deuterium depletion. Ramnicu Valcea, Romania Conphys: 60-61, 2001.

19. Laskay G, Somlyai G, Jancsó G, et al: Reduced deuterium concentration of water stimulates $\mathrm{O}_{2}$-uptake and electrogenic $\mathrm{H}^{+}$-efflux in the aquatic macrophyte Elodea canadensis. Jpn J Deuterim Sci 10: 17-23, 2001.

20. Berdea P, Cuna S, Cazacu M, et al: Deuterium variation of human blood serum. Studia Universitatis Babes-Bolyal, Physica, Special Issue: 256-258, 2001.

21. Gyongyi Z and Somlyai G: Deuterium depletion can decrease the expression of C-mys Ha-ras and p53 gene in carcinogen-treated mice. In Vivo 14: 437-440, 2000. 